\title{
Salivary Immunoglobulin A Secretion and Polymeric Ig Receptor Expression in the Submandibular Glands Are Enhanced in Heat-Acclimated Rats
}

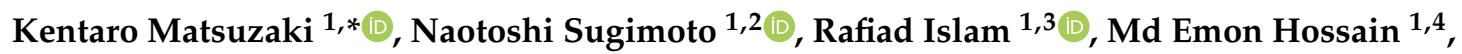 \\ Eri Sumiyoshi ${ }^{1}\left(\mathbb{D}\right.$, Masanori Katakura ${ }^{1,5}{ }^{\circledR}$ and Osamu Shido ${ }^{1}$ \\ 1 Department of Environmental Physiology, Faculty of Medicine, Shimane University, 89-1 Enya-cho, \\ Izumo 693-8501, Japan; ns@med.kanazawa-u.ac.jp (N.S.); rafiad@med.shimane-u.ac.jp (R.I.); \\ emon@uab.edu (M.E.H.); erisumi@med.shimane-u.ac.jp (E.S.); mkatakur@josai.ac.jp (M.K.); \\ o-shido@med.shimane-u.ac.jp (O.S.) \\ 2 Department of Physiology, Graduate School of Medical Science, Kanazawa University, 13-1 Takara-machi, \\ Kanazawa 920-8640, Japan \\ 3 Department of Biotechnology and Genetic Engineering, \\ Mawlana Bhashani Science and Technology University, Tangail 1902, Bangladesh \\ 4 Department of Biochemistry and Molecular Genetics, University of Alabama at Birmingham, Birmingham, \\ AL 35294, USA \\ 5 Department of Nutritional Physiology, Faculty of Pharmaceutical Sciences, Josai University, 1-1 Keyakidai, \\ Sakado, Saitama 350-0295, Japan \\ * Correspondence: matuzaki@med.shimane-u.ac.jp; Tel.: +81-853-20-2114
}

Received: 24 December 2019; Accepted: 25 January 2020; Published: 27 January 2020

check for updates

\begin{abstract}
Salivary immunoglobulin A (IgA) plays a critical role in mucosal immunity. Chronic exposure to moderate heat induces heat acclimation, which modifies salivary functions. However, the changes in salivary IgA secretion in heat-acclimated rats are unclear. In this study, we investigated salivary IgA secretion and the expression of polymeric Ig receptor (pIgR), a key mediator of mucosal IgA secretion, in the submandibular glands (SMGs) of heat-acclimated rats. Following maintenance at an ambient temperature $\left(\mathrm{T}_{\mathrm{a}}\right)$ of $24 \pm 0.1^{\circ} \mathrm{C}$ for 10 days, male Wistar rats were subjected to $\mathrm{T}_{\mathrm{a}}$ of $32 \pm 0.2{ }^{\circ} \mathrm{C}$ for 5 days (HE group) for heat acclimation or maintained at $\mathrm{T}_{\mathrm{a}}$ of $24 \pm 0.1^{\circ} \mathrm{C}$ (CN group) The rats were then anesthetized, pilocarpine $(0.5 \mathrm{mg} / \mathrm{kg})$ was intraperitoneally injected, and saliva was collected. Afterward, the SMGs and plasma were sampled. The salivary IgA concentration and IgA flow rate were significantly higher in the HE group than in the CN group. Similarly, SMG pIgR expression was significantly higher in HE rats. The levels of plasma cytokines, including interleukin (IL)-5, IL-6, and interferon- $\gamma$, were significantly greater in HE rats than in CN rats. Heat acclimation may enhance oral immunity through salivary IgA secretion and pIgR upregulation in the SMGs.
\end{abstract}

Keywords: saliva; immunoglobulin A; polymeric Ig receptor; heat acclimation; submandibular gland

\section{Introduction}

Immunoglobulin A (IgA) is a type of antibody that mainly functions in the mucosal immune system and serves as the first line of defense in protecting the oral cavity and upper respiratory tract [1,2]. Because plasma cells in salivary glands produce $\operatorname{IgA}$, there is a large amount of $\operatorname{IgA}$ in saliva [3]. The molecular mechanism of salivary IgA secretion has been studied in detail. Briefly, monomers of IgA form dimeric IgA (dIgA) through the J chain. dIgA binds the polymeric immunoglobulin receptor (pIgR) on the basolateral surface of epithelial cells and forms the IgA-pIgR complex. The IgA-pIgR complex is transported to the lumen from the basolateral surface. When pIgR reaches the apical 
membrane, proteolytic cleavage occurs at the apical surface. A fragment of pIgR becomes a secretory component (SC) that binds dIgA. In this manner, secretory $\operatorname{IgA}(\mathrm{sIgA})$ combines with other SCs, and free SCs are released. As a result, sIgA binds to luminal bacteria and prevents them from accessing the epithelial surface [4,5]. Therefore, a reduction in salivary sIgA levels grants bacteria access to the epithelial surface and leads to various diseases such as upper respiratory tract infection and periodontal disease $[6,7]$.

Most studies to date have focused on the critical role of pIgR as a key mediator of mucosal IgA secretion in humans and rodents [5]. Transcriptional regulation of $\mathrm{pIgR}$ is modulated by multiple factors, e.g., cytokines, hormones, and bacterial products, which activate innate immunity $[4,5]$. In particular, the primary regulators of $\mathrm{pIgR}$ expression are immune system cytokines, such as interleukin (IL)- $1 \beta$, IL-4, IL-5, IL-6, interferon- $\gamma$ (IFN $\gamma$ ), and tumor necrosis factor- $\alpha$ (TNF $\alpha)$ [8-11]. Hormones such as glucocorticoids (GCs) also regulate pIgR expression [12]. Moderate exercise increases IgA secretion and the expression level of pIgR in the submandibular glands (SMGs) $[13,14]$. In addition, enhanced susceptibility to Salmonella and Giardia infection and increased mortality have been reported in pIgR knockout (KO) mice $[15,16]$.

During increases in ambient temperature $\left(\mathrm{T}_{\mathrm{a}}\right)$ or core body temperature $\left(\mathrm{T}_{\text {core }}\right)$, rodents have been known to spread saliva on their skin, thereby counteracting a rise in their $\mathrm{T}_{\text {core }}$ as a substitute for sweat $[17,18]$. Conversely, numerous animals can adapt physiologically and biochemically when chronically exposed to moderate heat. This process, named heat acclimation, is known to increase endurance during acute heat stress [19-23]. In heat-acclimated rats, the functional and morphological changes of the SMG during thermoregulation have been studied in detail [24-27]. However, functional changes in oral immunity, namely salivary sIgA secretion and pIgR expression in the SMGs of heat-acclimated rats, are unclear. Therefore, this study investigated whether heat acclimation changes salivary IgA secretion and PIgR expression in the SMGs of rats.

\section{Results}

\section{1. $T_{\text {core }}$ and Locomotor Activity}

Before starting heat exposure, we first observed that $\mathrm{T}_{\text {core }}$ did not differ between control $(\mathrm{CN})$ and heat-exposed (HE) rats (Figure 1A). Mean $\mathrm{T}_{\text {core }}$ in the light and dark phase of $\mathrm{CN}$ and $\mathrm{HE}$ also did not differ between the groups (Figure 1A, light phase, $p=0.80$; dark phase, $p=0.80$ ). As shown in Figure 1B, locomotor activity did not differ between the groups before heat exposure in both the light and dark phases (Figure 1B, light phase, $p=0.80$; dark phase, $p=0.57$ ). Heat exposure significantly increased $\mathrm{T}_{\text {core }}$ (Figure $\left.1 \mathrm{C}\right)$ in both the light $(p<0.05)$ and dark phases $(p<0.05)$. During heat exposure, $\mathrm{T}_{\text {core }}$ was consistently higher in the HE group than in the CN group (Supplementary Figure S1). Conversely, heat exposure decreased locomotor activity (Figure 1D) in both the light $(p<0.05)$ and dark phases $(p<0.05)$. 
A

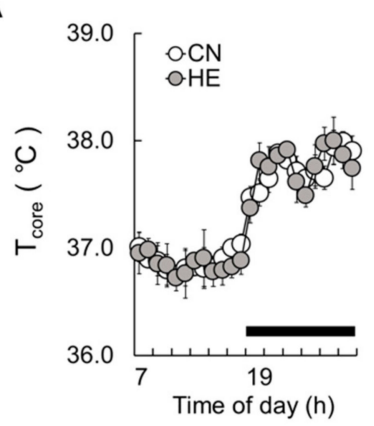

C

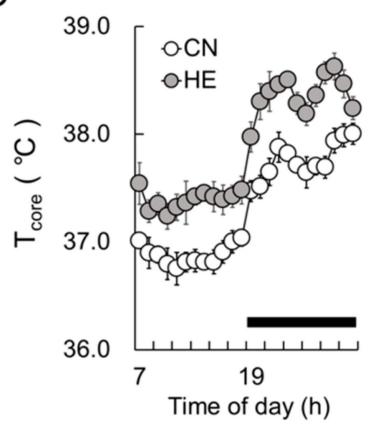

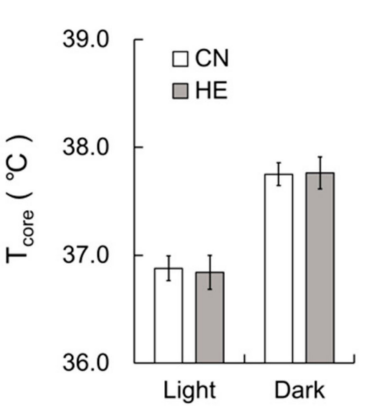

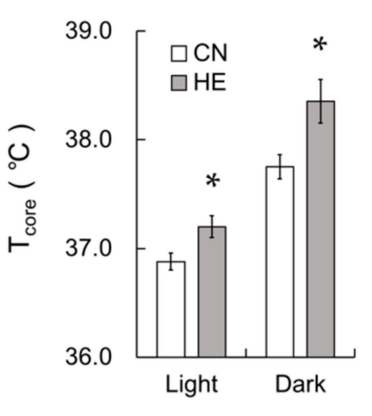

B

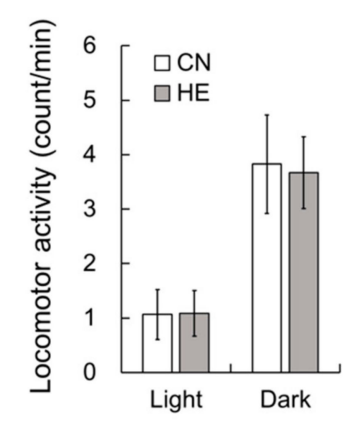

$\mathrm{D}$

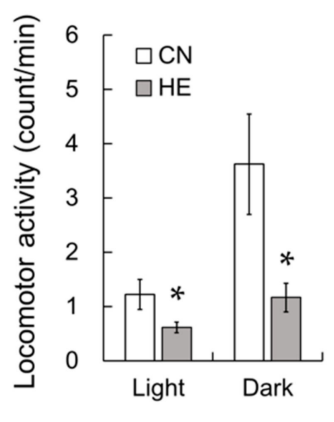

Figure 1. The core body temperature $\left(\mathrm{T}_{\text {core }}\right)$ and locomotor activity of control $(\mathrm{CN})$ and heat-exposed (HE) rats. (A) The left graph shows $\mathrm{T}_{\text {core }}$ of $\mathrm{CN}$ (open circle) and $\mathrm{HE}$ (gray circle) rats measured 1 day before the heat exposure period. The right graph presents mean $\mathrm{T}_{\text {core }}$ in the light (Light) and dark phases (Dark) in the $\mathrm{CN}$ (open column) and HE groups (gray column). (B) Locomotor activity of $\mathrm{CN}$ (open column) and HE rats (gray column). $\mathrm{T}_{\text {core }}$ and locomotor activity for (A) and (B) were measured 1 day before heat exposure. (C) The left graph indicates $\mathrm{T}_{\text {core }}$ in the $\mathrm{CN}$ and $\mathrm{HE}$ groups during heat exposure. The right graph presents mean $\mathrm{T}_{\text {core }}$ in the light and dark phases in the $\mathrm{CN}$ (open column) and HE groups (gray column) during heat exposure. Dark bars above the abscissa indicate the dark phase data. (D) Locomotor activity in the $\mathrm{CN}$ (open column) and HE groups (gray column). $\mathrm{T}_{\text {core }}$ and locomotor activity for (C) and (D) were measured on 2nd to 5 th day of heat exposure and summarized for 24 hours. Values are presented as the mean $\pm \operatorname{SEM}\left(n=8\right.$ in each group). ${ }^{*} p<0.05$, significant difference between the $\mathrm{CN}$ and $\mathrm{HE}$ groups.

\subsection{Body, $S M G$, and Adrenal Gland (AG) Weight}

After the heat exposure period, body, SMG, and AG weight were measured in the CN and HE groups as summarized in Table 1. The SMG and AG weights were normalized on the body weight (g) of same rats. AG weight was measured as a stress marker [28]. Heat exposure had no significant effects on their weight, although AG weight was slightly higher in the HE group than in the CN group (Table 1).

Table 1. Body weight (BW), submandibular gland (SMG) and adrenal gland (AG) weight of the control $(\mathrm{CN})$ and heat-exposed (HE) rats.

\begin{tabular}{cccc}
\hline & CN & HE & $P$ Value \\
\hline BW $(\mathrm{g})$ & $310.7 \pm 3.2$ & $305.5 \pm 3.9$ & 0.083 \\
SMG/BW (mg/g) & $0.98 \pm 0.01$ & $1.00 \pm 0.02$ & 0.505 \\
AG/BW (mg/g) & $0.15 \pm 0.01$ & $0.16 \pm 0.01$ & 0.442 \\
\hline
\end{tabular}

There was no significant difference in BW, SMG/BW and AG/BW between the $\mathrm{CN}$ and HE groups. The SMG and AG weights were normalized on the BW of same rats. Values are presented as the mean \pm SEM ( $n=8$ in each group). 


\subsection{Blood Cell Counts}

White blood cell (WBC), red blood cell (RBC), and platelet counts (PLT), hemoglobin (HGB), hematocrit (HTC), mean corpuscular hemoglobin (MCH) levels and mean corpuscular hemoglobin concentration (MCHC) data for the two groups are summarized in Table 2. No significant differences for any of these blood components were noted between the $\mathrm{CN}$ and HE groups (Table 2).

Table 2. Blood cell components for the control (CN) and heat-exposed (HE) rats.

\begin{tabular}{cccc}
\hline & CN & HE & $P$ Value \\
\hline WBC $\left(\times 10^{2} / \mu \mathrm{L}\right)$ & $66.7 \pm 3.2$ & $68.5 \pm 3.9$ & 0.130 \\
RBC $\left(\times 10^{5} / \mu \mathrm{L}\right)$ & $86.0 \pm 3.6$ & $87.5 \pm 4.6$ & 0.579 \\
PLT $\left(\times 10^{4} / \mu \mathrm{L}\right)$ & $68.4 \pm 2.4$ & $65.7 \pm 4.8$ & 0.234 \\
HGB $(\mathrm{g} / \mathrm{dL})$ & $15.1 \pm 1.1$ & $15.5 \pm 0.8$ & 0.505 \\
HTC $(\%)$ & $48.0 \pm 2.8$ & $50.2 \pm 3.3$ & 0.161 \\
MVC $(\mathrm{fl})$ & $54.9 \pm 1.2$ & $55.4 \pm 1.5$ & 0.195 \\
MCH $(\mathrm{pg})$ & $17.5 \pm 1.0$ & $18.0 \pm 1.2$ & 0.234 \\
MCHC $(\mathrm{g} / \mathrm{dL})$ & $30.2 \pm 2.0$ & $31.8 \pm 2.1$ & 0.195 \\
\hline
\end{tabular}

WBC, white blood cell; RBC, red blood cell; PLT, platelets; HGB, hemoglobin; HTC, hematocrit; MCV, mean corpuscular volume; $\mathrm{MCH}$, mean corpuscular hemoglobin; $\mathrm{MCHC}$, mean corpuscular hemoglobin concentration. There was no significant difference in any blood cell component between the $\mathrm{CN}$ and HE groups. Values are presented as the mean $\pm \operatorname{SEM}$ ( $n=8$ in each group).

\subsection{IgA Concentration in the Saliva, SMGs and Plasma}

IgA levels in the saliva, SMG tissue, and plasma were measured via enzyme-linked immunosorbent assay (ELISA). The salivary IgA concentration was significantly different between the $\mathrm{CN}$ and HE groups (Figure $2 \mathrm{~A}, p<0.05$ ). The IgA flow rate was significantly higher in the HE group than the $\mathrm{CN}$ group (Figure $2 \mathrm{~B}, p<0.05$ ). The SMG IgA concentration was also significantly higher in the HE group (Figure 2C, $p<0.05$ ), whereas no difference in the plasma IgA concentration was observed between the groups (Figure 2D, $p=0.80$ ).

A

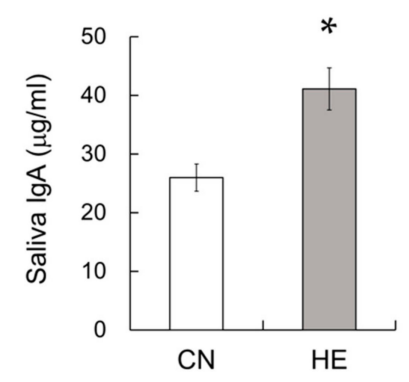

C

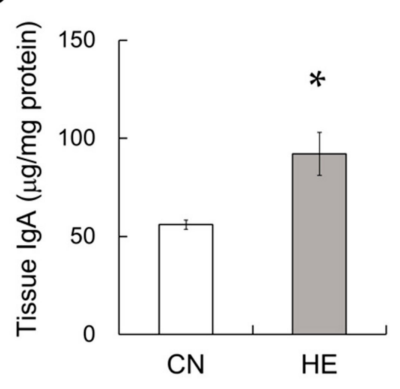

B

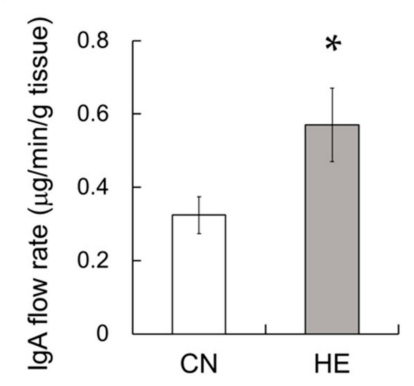

$\mathrm{D}$

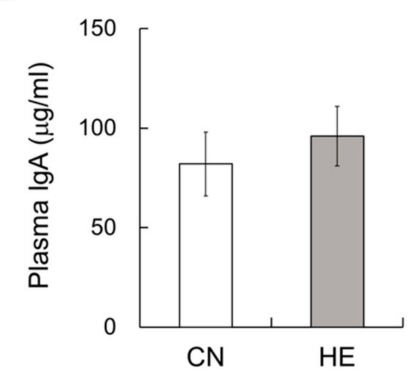

Figure 2. Salivary immunoglobulin A (IgA), IgA flow rate, IgA in the submandibular glands (SMGs) and plasma IgA levels in control $(\mathrm{CN})$ and heat-exposed (HE) rats. (A) IgA concentration in saliva. (B) IgA flow rate. (C) IgA concentration of the SMGs and (D) plasma. Values are presented as the mean $\pm \operatorname{SEM}\left(n=8\right.$ in each group). ${ }^{*} p<0.05$, significant difference between the CN and HE groups. 


\section{5. pIgR Expression in the SMGs}

To test whether pIgR expression is modulated by heat exposure, we examined pIgR protein expression in the SMGs. We examined pIgR protein expression in the SMGs via Western blotting using an anti-pIgR antibody. pIgR protein expression was significantly higher in the HE group than in the $\mathrm{CN}$ group (Figure $3 \mathrm{~A}, p<0.05$ ). Immunohistochemical analysis illustrated that $\mathrm{pIgR}$ was expressed in demilune structures in the salivary gland and weakly expressed in serous acinar cells, as described previously [29], and pIgR expression was markedly upregulated in the HE group compared with that in the $\mathrm{CN}$ group (Figure $3 \mathrm{~B}$ ).

A
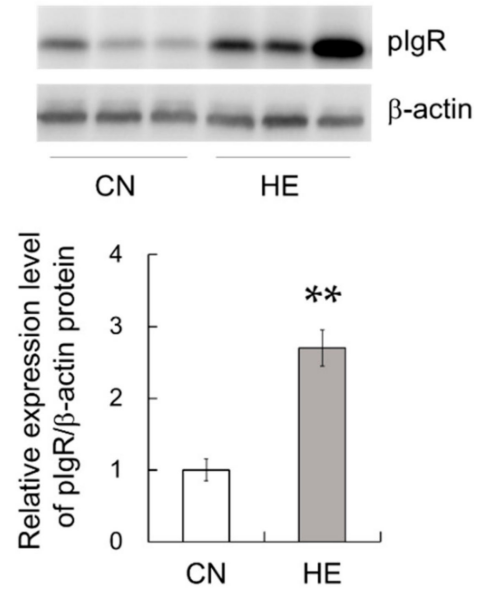

B
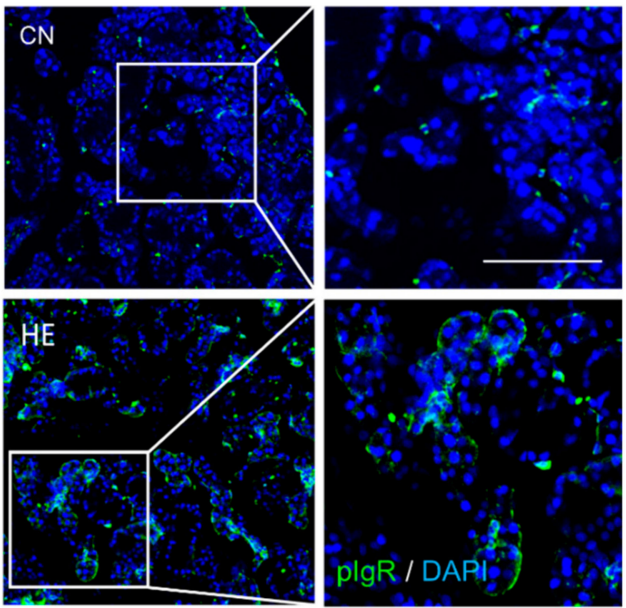

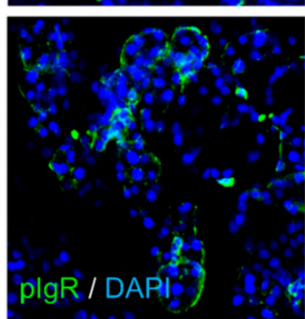

Figure 3. Polymeric immunoglobulin receptor (pIgR) expression in the submandibular glands (SMGs) of control (CN) and heat-exposed (HE) rats. (A) pIgR protein expression in the SMGs. Heat exposure increased pIgR protein expression in the SMGs. Left 3 lanes show $\mathrm{CN}$ rats, and right 3 lanes show HE rats. Values are presented as the mean $\pm \operatorname{SEM}\left(n=8\right.$ in each group). ${ }^{* *} p<0.01$, significant difference between the $\mathrm{CN}$ and HE groups. (B) Immunohistochemical analysis of pIgR (green) in the SMGs. The nuclei were stained with 4',6-diamidino-2-phenylindole (DAPI, blue). The right panel shows magnified views of the boxed regions from the $\mathrm{CN}$ and HE groups. Scale bar, $25 \mu \mathrm{m}$.

\subsection{Plasma Cytokine Levels}

pIgR expression is critically regulated by cytokines, such as IL-1 $\beta$, IL-4, IL-5, IL-6, IFN $\gamma$, and $\mathrm{TNF} \alpha$ [8-11]. To elucidate the mechanism regulating pIgR upregulation in the SMGs, plasma cytokine levels including IL-1 $\beta$, IL-4, IL-5, IL-6, IFN $\gamma$, and TNF $\alpha$ were measured in both groups. Plasma IL-5, IL-6, and IFN $\gamma$ levels were significantly higher in the HE group than in the CN group, whereas IL-1 $\beta$, IL-4, TNF $\alpha$ levels were not significantly changed by heat exposure (Figure 4). We could not detect any cytokines in the saliva of both $\mathrm{CN}$ and HE rats. 


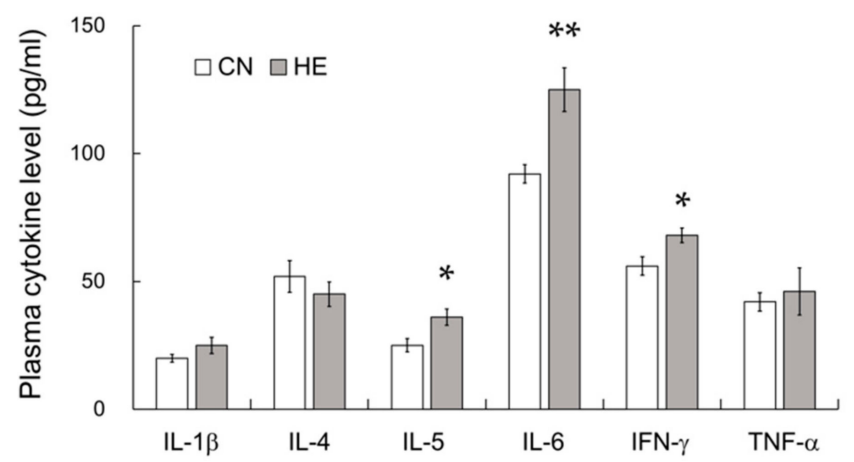

Figure 4. Plasma cytokine levels of control $(\mathrm{CN})$ and heat-exposed (HE) rats. Plasma interleukin (IL)-1 $\beta$, IL-4, IL-5, IL-6, interferon- $\gamma$ (IFN $\gamma$ ), and tumor necrosis factor- $\alpha$ (TNF $\alpha$ ) levels in the CN and HE groups. Plasma IL-5, IL-6, and IFN $\gamma$ expression was significantly higher in the HE group than in the CN group. Values are presented as the mean $\pm \operatorname{SEM}\left(n=8\right.$ in each group). ${ }^{*} p<0.05,{ }^{* *} p<0.01$, significant difference between the $\mathrm{CN}$ and $\mathrm{HE}$ groups.

\subsection{Plasma GC and GC Receptor (GR) Levels in the SMGs}

It has been reported that the $5^{\prime}$-flanking region of the pigr gene contains a response element to GCs [12]. This class of hormones, which includes corticosterone, is known to increase the expression of pIgR [4]. Thus, plasma GC levels were measured in CN and HE rats using ELISA. The plasma GC level was significantly higher in the HE group than in the CN group (Figure 5A), whereas GR protein level in the SMGs was not changed by heat exposure (Figure 5B).
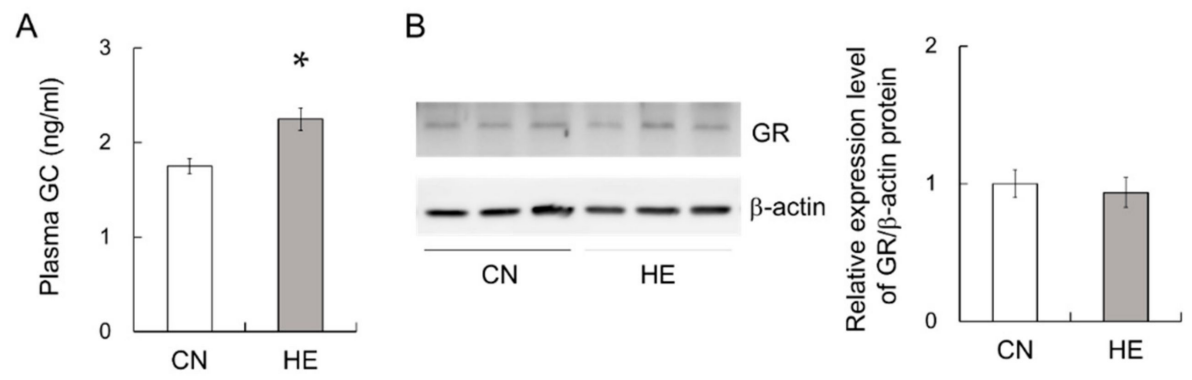

Figure 5. Plasma glucocorticoid (GC) level and glucocorticoid receptor (GR) expression in the submandibular glands (SMGs) of control (CN) and heat-exposed (HE) rats. (A) Plasma GC level in the $\mathrm{CN}$ and HE groups. Heat exposure significantly increased the plasma GC level in the rats. (B) GR protein expression in the SMGs. Heat exposure did not change GR protein expression level in the SMGs. Left 3 lanes show $\mathrm{CN}$ rats, and right 3 lanes show HE rats. ${ }^{*} p<0.05$, significant difference between the $\mathrm{CN}$ and HE groups. Values are presented as the mean $\pm \operatorname{SEM}(n=8$ in each group).

\subsection{Syndecan-1 (SDC-1) Expression in the SMGs}

SDC-1, also known as CD138, is a useful marker for plasma cells because it is expressed in the late stages of B-cell differentiation with progression toward plasma cells [30]. Because plasma cells produce IgA in the salivary glands [3], we analyzed SDC-1 expression in the SMGs. SDC-1 protein expression in the SMGs was significantly higher in the HE group than in the $\mathrm{CN}$ group (Figure 6A, $p<0.01$ ). The immunohistochemical analysis detected SDC-1 in plasma cells and a few epithelial cells exhibited cytoplasmic staining (Figure 6B). The number of SDC-1-positive cells was counted in randomly chosen high-power fields in each tissue and expressed as the number of cells per $\mathrm{mm}^{2}$. The number of SDC-1-positive cells in the SMGs was significantly higher in the HE group than in the $\mathrm{CN}$ group (Figure $6 \mathrm{~B}, p<0.01$ ). In addition, many SDC-1-immunopositive cells were co-labeled with anti-IgA antibody (Supplementary Figure S2). 
A
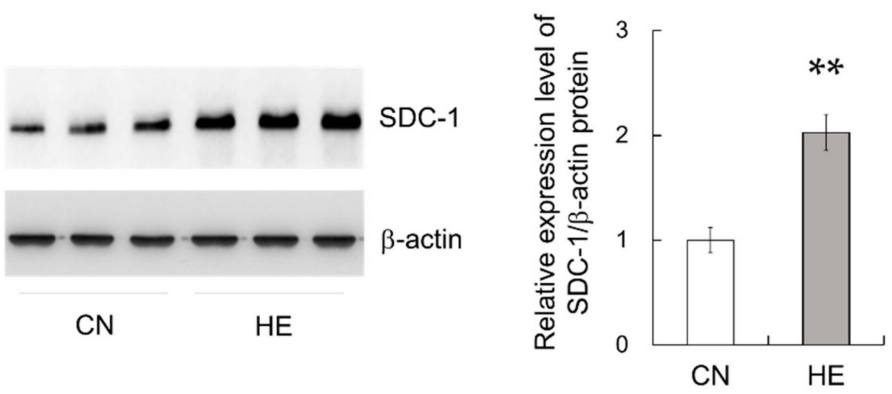

B
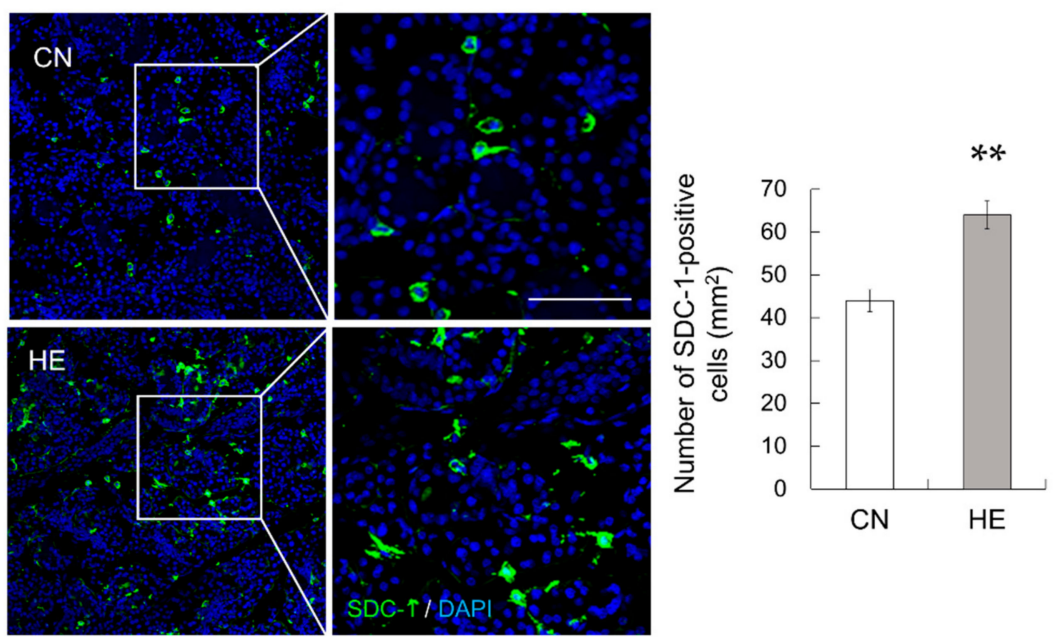

Figure 6. Syndecan-1 (SDC-1) expression in the submandibular glands (SMGs) of control (CN) and heat-exposed (HE) rats. (A) SDC-1 protein expression in the SMGs. Heat exposure increased SDC-1 protein expression in the SMGs. Left 3 lanes show $\mathrm{CN}$ rats and right 3 lanes show HE rats. (B) Immunohistochemical analysis of SDC-1 (green) in the SMGs. The nuclei were stained with 4',6-diamidino-2-phenylindole (DAPI, blue). The right panel shows magnified views of the boxed regions from the $\mathrm{CN}$ and HE groups. Right graph shows the density of SDC-1-immunopositive cells in the SMG sections. Values are presented as the mean $\pm \operatorname{SEM}\left(n=8\right.$ in each group). ${ }^{* *} p<0.01$, significant difference between $\mathrm{CN}$ and HE groups. Scale bar, $25 \mu \mathrm{m}$.

\subsection{Time Course Analysis of the Effect of Heat Exposure on IgA Secretion}

In a different series of the experiments, we additionally investigated that time-lapse of IgA secretion following 2, 7 and 14 days heat exposure. Before heat exposure, there were no significant differences in mean $\mathrm{T}_{\text {core }}$ between the groups. During the 2, 7 and 14 days heat exposure period, $\mathrm{T}_{\text {core }}$ in HE2, HE7, and HE14 rats were constantly higher than those in CN2, CN7, and CN14 rats, respectively (Figure $7 \mathrm{~A}, p<0.05$ ). The salivary IgA concentration (Figure $7 \mathrm{~B}, p<0.05$ ) and IgA flow rate (Figure $7 \mathrm{C}$, $p<0.05$ ) were increased during the first 2 days of the heat exposure period and remained elevated for at least 14 days. Body weight of HE14 rats was slightly lower than that of CN14, albeit without significance (Figure 7D, $p=0.232$ ). 
A

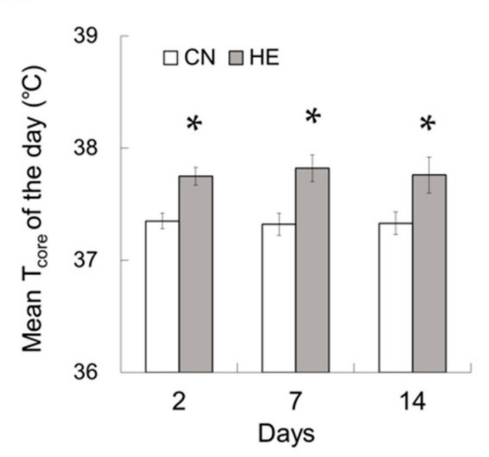

C

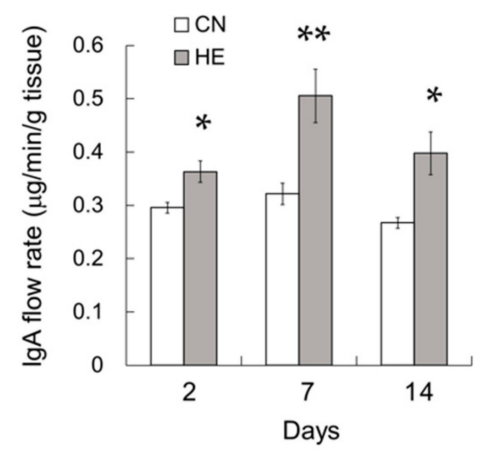

B

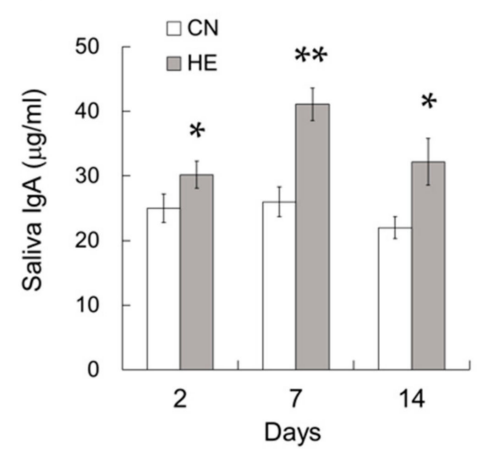

D

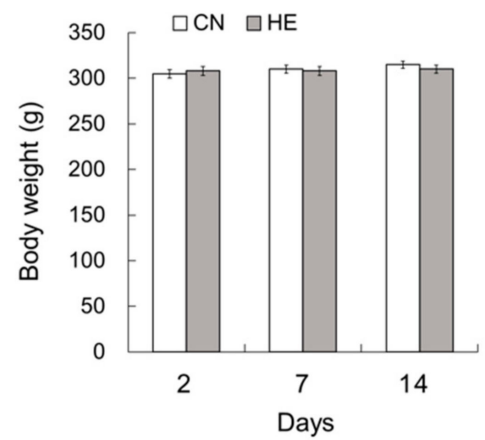

Figure 7. Time course analysis of the mean core body temperature $\left(\mathrm{T}_{\text {core }}\right)$, saliva IgA concentration, $\operatorname{Ig} \mathrm{A}$ flow rate, and pIgR expression in the submandibular glands (SMGs) of control (CN) and heat-exposed (HE) rats. (A) Mean $\mathrm{T}_{\text {core }}$ of $\mathrm{CN}$ and $\mathrm{HE}$ rats during the heat exposure period. $\mathrm{T}_{\text {core }}$ was measured at $2^{\text {nd }}, 7^{\text {th }}$ and $14^{\text {th }}$ day of heat exposure period. (B) Saliva IgA concentration. (C) Saliva IgA flow rate. The mean $\mathrm{T}_{\text {core, }} \mathrm{IgA}$ concentration and $\operatorname{IgA}$ flow rate were increased during the first 2 days of heat exposure and appeared to persist for at least 14 days. (D) Body weight of $\mathrm{CN}$ and HE rats. Values are presented as the mean $\pm \operatorname{SEM}\left(n=4\right.$ in each group). ${ }^{*} p<0.05,{ }^{* *} p<0.01$, significant difference between the $\mathrm{CN}$ and $\mathrm{HE}$ groups.

\section{Discussion}

In this study, we found that the salivary IgA concentration and IgA flow rate were significantly increased in heat-acclimated rats. The expression of $\mathrm{pIgR}$, a transcytosis regulator for $\operatorname{IgA}$, was also markedly enhanced in the SMGs of HE rats. Salivary IgA secretion increased in the first 2 days of the heat exposure period and remained elevated for at least 14 days. These results suggest that salivary IgA secretion may be promoted by pIgR upregulation in the SMGs of heat-acclimated rats. It is well known that the transcription of pIgR is critically regulated by cytokines [8-11]. We therefore investigated whether heat acclimation changes plasma cytokine levels in rats. IL-5, IL-6, and IFN $\gamma$ levels were significantly increased in the plasma of heat-acclimated rats compared with those in $\mathrm{CN}$ rats, whereas plasma IL-1 $\beta$, IL-4 and TNF $\alpha$ expression was unchanged. Changes in cytokine levels in HE rats may be involved in the changes of $\mathrm{pIgR}$ expression in the SMGs and IgA secretion. Given that heat stimulation induces IL-6 upregulation in the muscle [31,32], the source of plasma cytokine upregulation in HE rats may at least partly muscle-derived. It may be important to examine cytokine expression of the SMG, muscle and whole-body organs in heat-acclimated rats. We also found that the expression of SDC-1 was upregulated in the SMGs of HE rats. In addition, many SDC-1-immunopositive cells were co-labeled with IgA antibody. Because plasma cells in the salivary glands produce $\operatorname{IgA}$ [3], the upregulation of SDC-1 in HE rats may induce the increase of IgA production and secretion. Although the detailed mechanism of SDC-1 upregulation in the SMG is unknown, elevated cytokine may be involved in the promotion of B-cell differentiation to plasma cells. For example, IL-6 is well known to promote B-cell 
differentiation into plasma cells [33]. Further investigation of the effects of heat stimulation on B-cell differentiation into plasma cells is required.

Meanwhile, continuous exposure to moderate heat $\left(32{ }^{\circ} \mathrm{C}\right)$ could represent a mild stress in rats. Stress exposure activates a variety of physiological coping systems including the hypothalamic-pituitary-adrenal (HPA) axis [28]. Adrenal GCs released during stress, such as corticosterone, induce HPA axis activation and exert profound effects on immune functioning [28]. Stress responses typically promote IgA secretion, among other short-term body defense systems [34,35]. Investigations into immune changes in response to stress commonly employ sIgA as a marker of immune activation $[36,37]$. In this study, the plasma GC level was significantly higher in the HE group than in the CN group, whereas GR protein expression was not modulated. The AG wet weight was slightly higher in the HE group, albeit without significance. Because GC is involved in the regulation of pIgR transcription [12], the promotion of IgA secretion and pIgR expression in heat-acclimated rats might depend on both increased cytokine expression and GC production. It may be necessary to verify IgA secretion following moderate heat exposure in adrenalectomized rats. However, severe stress typically leads to deleterious health consequences, including decreases in sIgA levels [38]. It has also been reported that exposure to intense heat $\left(40^{\circ} \mathrm{C}\right)$ reduces intestinal $\operatorname{IgA}$ secretion and induces mucosal immune dysfunction in rats [39], suggesting that the promotion or suppression of $\operatorname{IgA}$ secretion depends on the level of heat stress. Changes in the ratio of salivary IgA secretion under different $\mathrm{T}_{\mathrm{a}}$ conditions should be studied in the future.

Salivary IgA secretion is rhythmically controlled by sympathetic nerve activation by the suprachiasmatic nucleus, which functions as the main oscillator of circadian rhythms $[40,41]$. The circadian rhythms of pIgR expression and IgA secretion in mice peaked during the light period, and the circadian control of salivary IgA secretion vanished in clock KO mice [41]. In the present study, the secreted saliva of both $\mathrm{CN}$ and HE rats was consistently collected in the light phase. In addition, heat exposure did not affect the daily $\mathrm{T}_{\text {core }}$ variation (rhythm) of rats. However, it may be required to explore whether heat exposure affects clock gene expression of the SMGs in a future.

In the oral cavity, heat shock protein 70 (HSP70) has a role of mucosal defense including entrapping, agglutinating, and opsonizing bacteria and inhibiting pathogenic adhesion to the mucosal surface [42-44]. Salivary HSP70 binds both gram-positive (Streptococcus mutans and Streptococcus mitis) and gram-negative (Escherichia coli) bacteria [42,43,45]. It was also reported that HSP70 in saliva is largely produced by the SMGs, mucosal cells, and periodontal tissues [42,44]. In salivary glands and periodontal tissues, epithelial cells and myoepithelial cells express HSP70, whereas HSP70 is not expressed in acinic cells $[44,46]$. We have previously reported that HSP70 protein in the SMGs is significantly upregulated in heat-acclimated rats [27]. We therefore investigated whether heat acclimation modifies the expression level of HSP70 in saliva. Our preliminary survey revealed that salivary HSP70 expression was significantly elevated in heat-acclimated rats (Supplementary Figure S3). Heat exposure may strengthen oral immunity by both increasing IgA secretion and enhancing HSP70 secretion in the saliva. Further investigations may be required to clarify the exact source of salivary HSP70 in heat-acclimated rats and whether elevated HSP70 expression in saliva and SMGs in heat-acclimated animals contributes to preventing oral infections.

\section{Materials and Methods}

\subsection{Ethics Statement}

All animal experiments in this study were performed in accordance with the Guidelines for Animal Experimentation of the Shimane University Faculty of Medicine in compliance with the Guidelines for Animal Experimentation of the Japanese Association for Laboratory Animal Science. The protocol for this study was approved by the Committee on the Ethics of Animal Experiments of Shimane University (Approval number: IZ30-56). 


\subsection{Experimental Schedule}

Sixteen male 10-week-old Wistar rats (Japan SLC Inc., Hamamatsu, Japan) were maintained for 7 days at $\mathrm{T}_{\mathrm{a}}$ of $24.0 \pm 0.1{ }^{\circ} \mathrm{C}$ and relative humidity of $45 \% \pm 5 \%$ under a 12-h:12-h light-dark cycle (light phase, 07:00-19:00) with food and water provided ad libitum. After 7 days post-arrival of the animals at the facility, rats were anesthetized using a combination anesthetic containing $0.15 \mathrm{mg} / \mathrm{kg}$ medetomidine (Kyoritsu Seiyaku, Tokyo, Japan), $2.0 \mathrm{mg} / \mathrm{kg}$ midazolam (Astellas Pharma, Tokyo, Japan), and $2.5 \mathrm{mg} / \mathrm{kg}$ butorphanol (Meiji Seika Pharma, Tokyo, Japan). Then, a TA10TA-F40 temperature transmitter (Data Sciences International, St Paul, MN, USA) was implanted in each rat's intraperitoneal cavity. Rats were allowed to recover from surgery for 14 days prior to data collection. After the recovery period, rats in the heat acclimation group (HE, $n=8$ ) were subjected to a constant $\mathrm{T}_{\mathrm{a}}$ of $32.0 \pm 0.2{ }^{\circ} \mathrm{C}$ for 5 days, whereas control rats $(\mathrm{CN}, n=8)$ were continuously maintained at $24.0 \pm 0.1{ }^{\circ} \mathrm{C}$, as described previously [47-49]. One day before, and during $2^{\text {nd }}$ to $5^{\text {th }}$ days of heat exposure period, $\mathrm{T}_{\text {core }}$ and locomotor activity were measured using a telemetry system $[50,51]$.

\subsection{Saliva Collection}

After the heat exposure period, saliva secretion induced by pilocarpine (Fujifilm Wako Pure Chemical, Tokyo, Japan) was collected as described previously [52]. Briefly, rats were weighed and anesthetized at approximately 10:00 h (light phase), a cotton ball was placed in their mouths sublingually, and pilocarpine $(0.5 \mathrm{mg} / \mathrm{kg})$ was intraperitoneally injected to induce saliva secretion. Pilocarpine, an M3 muscarinic receptor agonist, has been proven to be useful for inducing and assessing saliva secretion [52,53]. The cotton ball was then changed every $10 \mathrm{~min}$ for $1 \mathrm{~h}$. The 6 cotton balls collected from each rat were centrifuged, and saliva was collected.

\subsection{Blood and Tissue Collection}

After saliva collection, blood (approximately $4 \mathrm{~mL}$ ) was collected from the right ventricle of rats while anesthetized and placed into a sterile tube containing heparin sodium (Mochida Pharmaceutical Co., Ltd, Tokyo, Japan). Then, saline was transcardially perfused, and the SMGs and AGs were sampled and weighed. The right SMG was divided into two pieces and the entire half was used for immunohistochemistry and the rest for Western blotting and ELISA. The SMG sample for Western blotting and ELISA was flash frozen in liquid nitrogen and stored at $-80^{\circ} \mathrm{C}$ until use. The SMG for immunohistochemistry was fixed overnight in Mildform $10 \mathrm{~N}$ (Fujifilm Wako Pure Chemical) at $4{ }^{\circ} \mathrm{C}$ and immersed overnight in a 20\% (w/v) sucrose solution. Then, the SMGs were fixed in OCT compound (Sakura Finetek Japan Co., Ltd., Tokyo, Japan) and stored at $-30{ }^{\circ} \mathrm{C}$ until use.

\subsection{Blood Cell Counts}

After blood collection, $0.5 \mathrm{~mL}$ of blood sample was immediately used for blood cell counts. The following variables were measured in the $\mathrm{CN}$ and HE groups using a KX-21NV automatic hemocytometer (Sysmex, Kobe, Japan) as described previously [52,54]: WBC, RBC, PLT, HGB, HTC, $\mathrm{MCH}, \mathrm{MCHC}$ and $\mathrm{MCV}$. After blood cell counts, approximately $3.5 \mathrm{ml}$ of blood was centrifuged $(1500 \times \mathrm{g})$ for $20 \mathrm{~min}$ at $4{ }^{\circ} \mathrm{C}$. Plasma was collected, flash frozen in liquid nitrogen and stored at $-80^{\circ} \mathrm{C}$ until use.

\subsection{Western Blot Analysis}

The SMGs were homogenized using a glass homogenizer in lysis buffer containing $150 \mathrm{mM}$ sodium chloride, $1 \%$ Triton X-100, $0.1 \%$ sodium dodecyl sulfate (SDS), $1 \times$ protease inhibitor cocktail (Fujifilm Wako Pure Chemical), and $10 \mathrm{mM}$ Tris- $\mathrm{HCl}$ (pH 7.6). After sonication and removal of the tissue debris via centrifugation at $10,000 \times g$ for $15 \mathrm{~min}$ at $4^{\circ} \mathrm{C}$, the supernatants were analyzed via Western blotting as described previously [52]. Briefly, the concentrations of proteins extracted from the SMGs were determined using a Pierce BCA protein assay kit (Thermo Fisher Scientific, Waltham, MA, USA). 
Equal amounts of protein extracts were boiled in $6 \times$ SDS sample buffer (Nacalai Tesque, Kyoto, Japan). Samples were separated via $12.5 \%$ SDS-polyacrylamide gel electrophoresis. The resolved proteins were transferred onto polyvinylidene fluoride (PVDF) membranes (Millipore, Billerica, MA, USA) blocked with $5 \%$ skimmed milk and then incubated with primary antibodies, namely polyclonal rabbit anti-pIgR (1:1000; GeneTex Irvine, CA, USA), polyclonal rabbit anti-syndecan-1 (1:1000; BioVision, Milpitas, CA, USA), or monoclonal mouse anti-glucocorticoid receptor (1:1000; GeneTex), at $4{ }^{\circ} \mathrm{C}$ for $12 \mathrm{~h}$. After washing, the PVDF membranes were incubated with horseradish peroxidase-linked anti-mouse, anti-rabbit, or anti-goat secondary antibodies (1:2000; Cell Signaling, Danvers, MA, USA) at room temperature for $2 \mathrm{~h}$. The blots were developed using SuperSignal ${ }^{\mathrm{TM}}$ West Pico PLUS Chemiluminescent Substrate (Thermo Fisher Scientific) and visualized using a LAS 4000 visualizer imaging system (Fujifilm, Tokyo, Japan). The membranes were then stripped and reprobed with monoclonal rabbit anti- $\beta$-actin antibody (1:5000; Cell Signaling, Danvers, MA, USA) to ensure that equal amounts of protein were loaded. Each protein band was quantitated by imaging software Multi gauge Version 3.0 (Fujifilm), and the target protein was normalized on the $\beta$-actin expression of the same sample.

\subsection{ELISA}

The IgA concentration in saliva and SMG samples was measured using an IgA ELISA Kit (Abnova, Taipei, Taiwan) according to the manufacturer's protocol. The plasma GC concentration was measured using a General Glucocorticoid ELISA Kit (MyBioSource, San Diego CA, USA). Saliva HSP70 concentration was measured using a HSP70 ELISA kit (StressMarq Biosciences Inc. Victoria, British Columbia, Canada). Absorbance was measured using a DTX880 multi-mode microplate reader (Beckman Coulter, Pasadena, CA, USA). IgA, GC and HSP70 concentrations were calculated using SoftMax pro software (Molecular Devices, LLC, San Jose, CA, USA) as described previously [54,55]. The IgA flow rate in saliva ( $\mu \mathrm{g} / \mathrm{min} / \mathrm{g}$ SMG tissue) was calculated by multiplying the absolute concentration of $\operatorname{IgA}(\mu \mathrm{g} / \mathrm{mL})$ by the saliva flow rate $(\mathrm{mL} / \mathrm{min})$ as per $\mathrm{g}$ of SMG tissue.

\subsection{Immunohistochemistry}

A CM1520 cryostat (Leica, Wetzlar, Germany) was used to prepare $15-\mu$ m-thick SMG sections, which were then incubated in $10 \mathrm{mM}$ sodium citrate buffer ( $\mathrm{pH}$ 6.0) and blocked with $3 \%$ normal goat serum (Agilent, Santa Clara, CA, USA). For multiplex immunoassaying, the SMG sections were incubated with primary antibodies at $4{ }^{\circ} \mathrm{C}$ for $12 \mathrm{~h}$. The primary antibodies used in this study were polyclonal rabbit anti-pIgR (1:500), polyclonal goat anti-IgA (1:500, Novus Biologicals, LLC, Centennial, CO, USA), and monoclonal mouse anti-SDC-1 (1:500). Alexa Fluor 488-conjugated anti-mouse IgG (1:500; Molecular Probes, Waltham, MA, USA), Alexa Fluor 488-conjugated anti-rabbit IgG and Alexa Fluor 633-conjugated anti-goat IgG (1:500; Molecular Probes) were used as the secondary antibodies. To detect cell nuclei, sections were counterstained with 4',6-diamidino-2-phenylindole solution (DAPI, 1:2000, Dojindo, Kumamoto, Japan). After staining, the sections were washed and covered with 80\% glycerol. An FV-1000D confocal microscope (Olympus, Tokyo, Japan) and Fluoview imaging software (Olympus) were used to visualize all sections under $\times 20$ or $\times 40$ magnification, as described previously [52].

\subsection{Cytokine Measurements}

Plasma and saliva samples were assayed for cytokine concentrations using multiplexed (IL- $1 \beta$, IL-4, IL-5, IL-6, IFN $\gamma$, and TNF $\alpha$ ) bead-based immunoassay kits combined with a Cytokine Reagent Kit (Bio-Rad Laboratories, Hercules, CA, USA) and a Bio-Plex ${ }^{\mathrm{TM}}$ Diluent Kit (Bio-Rad Laboratories) in the Bio-Plex ${ }^{\mathrm{TM}}$ MAGPIX System (Bio-Rad Laboratories) according to the manufacturer's protocol. Concentrations of plasma cytokines were calculated using Bio-Plex ${ }^{\mathrm{TM}}$ Manager MP Software (Bio-Rad Laboratories). 


\subsection{Time Course Effects of Heat Exposure on IgA Secretion}

Additionally, 24 male Wistar rats (10 weeks old) were used to perform time-lapse analysis of IgA secretion following heat exposure. Rats were maintained for 7 days at $T_{a}$ of $24.0 \pm 0.1{ }^{\circ} \mathrm{C}$ and relative humidity of $45 \% \pm 5 \%$ under a 12-h:12-h light-dark cycle with food and water provided ad libitum. Then, all rats were anesthetized, and a telemetry transmitter was implanted into their abdominal cavities. After a 14-day recovery period, rats in the HE group were subjected to a constant $\mathrm{T}_{\mathrm{a}}$ of $32.0 \pm 0.2{ }^{\circ} \mathrm{C}$ and relative humidity of $45 \% \pm 5 \%$, whereas $\mathrm{CN}$ rats were continuously kept at $24.0 \pm 0.1^{\circ} \mathrm{C}$. On the 2nd (HE2), 7th (HE7), and 14th (HE14) days of the heat exposure period ( $n=4$ in each group), the rats were weighed and anesthetized, pilocarpine $(0.5 \mathrm{mg} / \mathrm{kg})$ was injected, and saliva was sampled as described previously. The same procedure was applied to control rats without heat exposure, i.e., the saliva was collected on the 2nd (CN2), 7th (CN7), and 14th (CN14) days ( $n=4$ in each group). Salivary IgA levels and the IgA flow rate were measured as described previously.

\subsection{Data Quantification and Statistical Analysis}

The results are presented as the mean \pm SEM. Statistical analyses were performed using SPSS software version 22.0 (IBM Corp., Armonk, NY, USA). The Mann-Whitney $U$ test was used for comparisons between 2 groups. Analysis of variance followed by Bonferroni's post hoc test was used to examine any significant group differences in time-lapse analysis of the effect of heat exposure on mean daily $\mathrm{T}_{\text {core, }}$ salivary IgA concentrations, IgA flow rates, and body weights. $p<0.05$ denoted statistical significance.

\section{Conclusions}

The results of this study demonstrated that constant exposure to moderate heat facilitated salivary IgA secretion and upregulated pIgR expression in the SMGs of rats. Although further research is required to elucidate the mechanism, heat acclimation enhances oral immune functions, and it may be beneficial for preventing upper respiratory tract infection and periodontal disease. Because body temperature and immune function are closely involved [56], it may be important to examine the immune function of both the salivary gland and whole-body organs in heat-acclimated animals.

Supplementary Materials: The following are available online at http://www.mdpi.com/1422-0067/21/3/815/s1, Figure S1: The $\mathrm{T}_{\text {core }}$ of $\mathrm{CN}$ and HE during heat exposure period, Figure S2: Double-staining of IgA and SDC-1 in the SMG of HE rat, Figure S3: Salivary HSP70 expression of CN and HE groups.

Author Contributions: Conceptualization, K.M., N.S. and O.S.; data curation, K.M.; formal analysis, K.M., R.I., M.E.H. and E.S.; funding acquisition, K.M. and O.S.; investigation, K.M., E.S. and N.S.; methodology, K.M. and N.S.; project administration, K.M.; resources, K.M., N.S., M.K. and O.S.; supervision, N.S. and O.S.; validation, N.S. and M.K.; writing - original draft, K.M.; all authors reviewed the manuscript. All authors have read and agreed to the published version of the manuscript.

Funding: This study was supported by a Ministry of Education, Culture, Sports, Science, and Technology of Japan Grant-in-Aid for Scientific Research (C) 15K08208, 15K08209 and 18K06853, and support funds of Shimane University for young researchers.

Acknowledgments: We thank M. Hashimoto, T. Hara and Y. Tanabe for their helpful support. We also would like to acknowledge the technical expertise of the Interdisciplinary Center for Science Research Organization for Research and Academic Information, Shimane University.

Conflicts of Interest: The authors declare no conflict of interests. 


\section{Abbreviations}

$\begin{array}{ll}\text { AG } & \text { Adrenal gland } \\ \text { CN } & \text { Control } \\ \text { ELISA } & \text { Enzyme-linked immunosorbent assay } \\ \text { GC } & \text { Glucocorticoid } \\ \text { GR } & \text { Glucocorticoid receptor } \\ \text { HE } & \text { Heat-exposed } \\ \text { HGB } & \text { Hemoglobin } \\ \text { HTC } & \text { Hematocrit } \\ \text { IFN } \gamma & \text { Interferon- } \gamma \\ \text { IgA } & \text { Immunoglobulin A } \\ \text { IL } & \text { Interleukin } \\ \text { MCH } & \text { Mean corpuscular hemoglobin } \\ \text { MCHC } & \text { Mean corpuscular hemoglobin concentration } \\ \text { MCV } & \text { Mean corpuscular volume } \\ \text { pIgR } & \text { Polymeric immunoglobulin receptor } \\ \text { PLT } & \text { Platelet } \\ \text { RBC } & \text { Red blood cell } \\ \text { SC } & \text { Secretory component } \\ \text { SMG } & \text { Submandibular gland } \\ \text { TNF } \alpha & \text { Tumor necrosis factor- } \alpha \\ \text { WBC } & \text { White blood cell }\end{array}$

\section{References}

1. Williams, R.C.; Gibbons, R.J. Inhibition of bacterial adherence by secretory immunoglobulin A: A mechanism of antigen disposal. Science 1972, 177, 697-699. [CrossRef] [PubMed]

2. Brandtzaeg, P. Do salivary antibodies reliably reflect both mucosal and systemic immunity? Ann. N. Y. Acad. Sci. 2007, 1098, 288-311. [CrossRef] [PubMed]

3. Macpherson, A.J.; McCoy, K.D.; Johansen, F.E.; Brandtzaeg, P. The immune geography of IgA induction and function. Mucosal Immunol. 2008, 1, 11-22. [CrossRef] [PubMed]

4. Johansen, F.E.; Kaetzel, C.S. Regulation of the polymeric immunoglobulin receptor and IgA transport: New advances in environmental factors that stimulate pIgR expression and its role in mucosal immunity. Mucosal Immunol. 2011, 4, 598-602. [CrossRef]

5. Turula, H.; Wobus, C.E. The role of the polymeric immunoglobulin receptor and secretory immunoglobulins during mucosal infection and immunity. Viruses 2018, 10, 237. [CrossRef]

6. Rose, P.T.; Gregory, R.L.; Gfell, L.E.; Hughes, C.V. IgA antibodies to Streptococcus mutans in caries-resistant and -susceptible children. Pediatr. Dent. 1994, 16, 272-275.

7. Neville, V.; Gleeson, M.; Folland, J.P. Salivary IgA as a risk factor for upper respiratory infections in elite professional athletes. Med. Sci. Sports Exerc. 2008, 40, 1228-1236. [CrossRef]

8. Sollid, L.M.; Kvale, D.; Brandtzaeg, P.; Markussen, G.; Thorsby, E. Interferon-gamma enhances expression of secretory component, the epithelial receptor for polymeric immunoglobulins. J. Immunol. 1987, 138, 4303-4306.

9. Kvale, D.; Lovhaug, D.; Sollid, L.M.; Brandtzaeg, P. Tumor necrosis factor-alpha up-regulates expression of secretory component, the epithelial receptor for polymeric Ig. J. Immunol. 1988, 140, 3086-3089.

10. Hayashi, M.; Takenouchi, N.; Asano, M.; Kato, M.; Tsurumachi, T.; Saito, T.; Moro, I. The polymeric immunoglobulin receptor (secretory component) in a human intestinal epithelial cell line is up-regulated by interleukin-1. Immunology 1997, 92, 220-225. [CrossRef]

11. Asano, M.; Komiyama, K. Polymeric immunoglobulin receptor. J. Oral Sci. 2011, 53, 147-156. [CrossRef] [PubMed]

12. Rincheval-Arnold, A.; Belair, L.; Cencic, A.; Djiane, J. Up-regulation of polymeric immunoglobulin receptor mRNA in mammary epithelial cells by IFN-gamma. Mol. Cell. Endocrinol. 2002, 194, 95-105. [CrossRef] 
13. Drago-Serrano, M.E.; Godínez-Victoria, M.; Lara-Padilla, E.; Resendiz-Albor, A.A.; Reyna-Garfias, H.; Arciniega-Martínez, I.M.; Kormanovski-Kovsova, A.; Campos-Rodriguez, R. Moderate exercise enhances expression of SIgA in mouse ileum. Int. J. Sports Med. 2012, 33, 1020-1025. [CrossRef] [PubMed]

14. Kurimoto, Y.; Saruta, J.; To, M.; Yamamoto, Y.; Kimura, K.; Tsukinoki, K. Voluntary exercise increases IgA concentration and polymeric Ig receptor expression in the rat submandibular gland. Biosci. Biotechnol. Biochem. 2016, 80, 2490-2496. [CrossRef]

15. Wijburg, O.L.; Uren, T.K.; Simpfendorfer, K.; Johansen, F.E.; Brandtzaeg, P.; Strugnell, R.A. Innate secretory antibodies protect against natural Salmonella typhimurium infection. J. Exp. Med. 2006, 203, 21-26. [CrossRef]

16. Davids, B.J.; Palm, J.E.; Housley, M.P.; Smith, J.R.; Andersen, Y.S.; Martin, M.G.; Hendrickson, B.A.; Johansen, F.E.; Svard, S.G.; Gillin, F.D.; et al. Polymeric immunoglobulin receptor in intestinal immune defense against the lumen-dwelling protozoan parasite Giardia. J. Immunol. 2006, 177, 6281-6290. [CrossRef]

17. Hainsworth, F.R. Saliva spreading, activity, and body temperature regulation in the rat. Am. J. Physiol. 1967, 212, 1288-1292. [CrossRef]

18. Almeida, M.C.; Cristiano, R.; Vizin, L.; Carrettiero, D.C. Current understanding on the neurophysiology of behavioral thermoregulation. Temperature 2015, 2, 483-490. [CrossRef]

19. Wyndham, C.H. Effect of acclimatization on the sweat rate-rectal temperature relationship. J. Appl. Physiol. 1967, 22, 27-30. [CrossRef]

20. Horowitz, M.; Kaspler, P.; Simon, E.; Gerstberger, R. Heat acclimation and hypohydration: involvement of central angiotensin II receptors in thermoregulation. Am. J. Physiol. 1999, 277, R47-R55. [CrossRef]

21. Sugimoto, N.; Shido, O.; Matsuzaki, K.; Ohno-Shosaku, T.; Hitomi, Y.; Tanaka, M.; Sawaki, T.; Fujita, Y.; Kawanami, T.; Masaki, Y.; et al. Cellular heat acclimation regulates cell growth, cell morphology, mitogen-activated protein kinase activation, and expression of aquaporins in mouse fibroblast cells. Cell. Physiol. Biochem. 2012, 30, 450-457. [CrossRef] [PubMed]

22. Shido, O.; Matsuzaki, K. Involvement of neurogenesis in the hypothalamic area in establishing long-term heat acclimation in rats. Temperature 2015, 3, 362-367. [CrossRef] [PubMed]

23. Shido, O.; Matsuzaki, K.; Katakura, M. Neurogenesis in the Thermoregulatory System. Handb. Clin. Neurol. 2018, 156, 457-463.

24. Horowitz, M.; Meiri, U. Thermoregulatory activity in the rat: effects of hypohydration, hypovolemia and hypertonicity and their interaction with short-term heat acclimation. Comp. Biochem. Physiol. A Comp. Physiol. 1985, 82, 577-582. [CrossRef]

25. Oron, Y.; Falach, O.; Marmary, I.; Horowitz, M. Long-term heat adaptation results in an enhanced efficiency of muscarinically-induced water secretion in rat submaxillary glands. Comp. Biochem. Physiol. A Comp. Physiol. 1989, 94, 673-676. [CrossRef]

26. Furuyama, F.; Murakami, M.; Oiwa, T.; Nishino, H. Differences in thermal salivation between the FOK rat (a model of genotypic heat adaptation) and three other rat strains. Physiol. Behav. 1998, 63, 787-793. [CrossRef]

27. Sugimoto, N.; Matsuzaki, K.; Ishibashi, H.; Tanaka, M.; Sawaki, T.; Fujita, Y.; Kawanami, T.; Masaki, Y.; Okazaki, T.; Sekine, J.; et al. Upregulation of aquaporin expression in the salivary glands of heat-acclimated rats. Sci. Rep. 2013, 3, 1763. [CrossRef]

28. Watanabe, T.; Fujioka, T.; Hashimoto, M.; Nakamura, S. Stress and brain angiotensin II receptors. Crit. Rev. Neurobiol. 1998, 12, 305-317. [CrossRef]

29. Mikami, Y.; Iwase, T.; Komiyama, Y.; Matsumoto, N.; Oki, H.; Komiyama, K. Secretory leukocyte protease inhibitor inhibits expression of polymeric immunoglobulin receptor via the NF- $\mathrm{KB}$ signaling pathway. Mol. Immunol. 2015, 67, 568-574. [CrossRef]

30. O'Connell, F.P.; Pinkus, J.L.; Pinkus, G.S. CD138 (syndecan-1), a plasma cell marker immunohistochemical profile in hematopoietic and nonhematopoietic neoplasms. Am. J. Clin. Pathol. 2004, 121, 254-263. [CrossRef]

31. Welc, S.S.; Phillips, N.A.; Oca-Cossio, J.; Wallet, S.M.; Chen, D.L.; Clanton, T.L. Hyperthermia increases interleukin-6 in mouse skeletal muscle. Am. J. Physiol. Cell. Physiol. 2012, 303, C455-C466. [CrossRef]

32. Obi, S.; Nakajima, T.; Hasegawa, T.; Kikuchi, H.; Oguri, G.; Takahashi, M.; Nakamura, F.; Yamasoba, T.; Sakuma, M.; Toyoda, S.; et al. Heat induces interleukin-6 in skeletal muscle cells via TRPV1/PKC/CREB pathways. J. App. Phys. 2017, 122, 683-694. [CrossRef] [PubMed] 
33. Hirano, T.; Yasukawa, K.; Harada, H.; Taga, T.; Watanabe, Y.; Matsuda, T.; Kashiwamura, S.; Nakajima, K.; Koyama, K.; Iwamatsu, A.; et al. Complementary DNA for a novel human interleukin (BSF-2) that induces B lymphocytes to produce immunoglobulin. Nature 1986, 324, 73-76. [CrossRef] [PubMed]

34. Willemsen, G.; Ring, C.; Carroll, D.; Evans, P.; Clow, A.; Hucklebridge, F. Secretory immunoglobulin A and cardiovascular reactions to mental arithmetic and cold pressor. Psychophysiology 1998, 35, 252-259. [CrossRef] [PubMed]

35. Zeier, H.; Brauchli, P.; Joller-Jemelka, H.I. Effects of work demands on immunoglobulin A and cortisol in air traffic controllers. Biol. Psychol. 1996, 42, 413-423. [CrossRef]

36. Yamamoto, S.; Motomura, A.; Akahoshi, A.; Takahashi, K.; Minami, H. Immunoglobulin secretions in the mesenteric lymph node in stressed rats. J. Nutr. Sci. Vitaminol. 2009, 55, 191-194. [CrossRef]

37. Laurent, H.K.; Stroud, L.R.; Brush, B.; D’Angelo, C.; Granger, D.A. Secretory IgA reactivity to social threat in youth: relations with HPA, ANS, and behavior. Psychoneuroendocrinology 2015, 59, 81-90. [CrossRef]

38. Campos-Rodríguez, R.; Godínez-Victoria, M.; Abarca-Rojano, E.; Pacheco-Yépez, J.; Reyna-Garfias, H.; Barbosa-Cabrera, R.E.; Drago-Serrano, M.E. Stress modulates intestinal secretory immunoglobulin A. Front. Integr. Neurosci. 2013, 7, 86. [CrossRef]

39. Liu, X.; Li, H.; Lu, A.; Zhong, Y.; Hou, X.; Wang, N.; Jia, D.; Zan, J.; Zhao, H.; Xu, J.; et al. Reduction of intestinal mucosal immune function in heat-stressed rats and bacterial translocation. Int. J. Hyperthermia 2012, 28, 756-765. [CrossRef]

40. Furukawa, M.; Kawamoto, T.; Noshiro, M.; Honda, K.K.; Sakai, M.; Fujimoto, K.; Honma, S.; Honma, K.; Hamada, T.; Kato, Y. Clock gene expression in the submandibular glands. J. Dent. Res. 2005, 84, 1193-1197. [CrossRef]

41. Wada, M.; Orihara, K.; Kamagata, M.; Hama, K.; Sasaki, H.; Haraguchi, A.; Miyakawa, H.; Nakao, A.; Shibata, S. Circadian clock-dependent increase in salivary IgA secretion modulated by sympathetic receptor activation in mice. Sci. Rep. 2017, 7, 8802. [CrossRef]

42. Fábián, T.K.; Hermann, P.; Beck, A.; Fejerdy, P.; Fabian, G. Salivary defense proteins: their network and role in innate and acquired oral immunity. Int. J. Mol. Sci. 2012, 13, 4295-4320. [CrossRef] [PubMed]

43. Fábián, T.K.; Sőti, C.; Nguyen, M.T.; Csermely, P.; Fejérdy, P. Expected functions of salivary HSP70 in the oral cavity. In Heat Shock Proteins: New Research, 1st ed.; Morel, E., Vincent, C., Eds.; Nova Science Publishers, Inc.: New York, NY, USA, 2008; pp. 321-340.

44. Fábián, T.K.; Beck, A.; Fejérdy, P.; Hermann, P.; Fábián, G. Molecular mechanisms of taste recognition: considerations about the role of saliva. Int. J. Mol. Sci. 2015, 16, 5945-5974. [CrossRef] [PubMed]

45. Anand, P.K.; Anand, E.; Bleck, C.K.E.; Anes, E.; Griffiths, G. Exosomal Hsp70 induces a pro-inflammatory response to foreign particles including mycobacteria. PLOS ONE 2010, 5, e10136. [CrossRef] [PubMed]

46. Vanmuylder, N.; Evrard, L.; Daelemans, P.; Dourov, N. Chaperones in the Parotid Gland: Localization of Heat Shock Proteins in Human Adult Salivary Glands. Cells Tissues Organs 2000, 167, 199-205. [CrossRef] [PubMed]

47. Li, G.H.; Katakura, M.; Maruyama, M.; Enhkjargal, B.; Matsuzaki, K.; Hashimoto, M.; Shido, O. Changes of noradrenaline-induced contractility and gene expression in aorta of rats acclimated to heat in two different modes. Eur. J. Appl. Physiol. 2008, 104, 29-40. [CrossRef]

48. Matsuzaki, K.; Katakura, M.; Hara, T.; Li, G.; Hashimoto, M.; Shido, O. Proliferation of neuronal progenitor cells and neuronal differentiation in the hypothalamus are enhanced in heat-acclimated rats. Pflüg. Arch. 2009, 458, 661-673. [CrossRef]

49. Matsuzaki, K.; Katakura, M.; Inoue, T.; Hara, T.; Hashimoto, M.; Shido, O. Aging attenuates acquired heat tolerance and hypothalamic neurogenesis in rats. J. Comp. Neurol. 2015, 523, 1190-1201. [CrossRef]

50. Matsuzaki, K.; Katakura, M.; Sugimoto, N.; Hara, T.; Hashimoto, M.; Shido, O. $\beta$-amyloid infusion into lateral ventricle alters behavioral thermoregulation and attenuates acquired heat tolerance in rats. Temperature 2015, 2, 418-424. [CrossRef]

51. Matsuzaki, K.; Katakura, M.; Sugimoto, N.; Hara, T.; Hashimoto, M.; Shido, O. Neural progenitor cell proliferation in the hypothalamus is involved in acquired heat tolerance in long-term heat-acclimated rats. PLOS ONE 2017, 12, e0178787. [CrossRef]

52. Matsuzaki, K.; Sugimoto, N.; Katakura, M.; Sumiyoshi, E.; Hara, T.; Hashimoto, M.; Shido, O. Daily voluntary exercise enhances pilocarpine-induced saliva secretion and aquaporin 1 expression in rat submandibular glands. FEBS Open Bio. 2018, 8, 85-93. [CrossRef] 
53. Ishii, H.; Nakagawa, Y. Stress response to surgical procedures in the submandibular region and its influence on saliva secretion in mice. Arch. Oral Biol. 2001, 46, 387-390. [CrossRef]

54. Islam, R.; Matsuzaki, K.; Sumiyoshi, E.; Hossain, M.E.; Hashimoto, M.; Katakura, M.; Sugimoto, N.; Shido, O. Theobromine improves working memory by activating the CaMKII/CREB/BDNF pathway in rats. Nutrients 2019, 11, E888. [CrossRef] [PubMed]

55. Hossain, M.E.; Matsuzaki, K.; Katakura, M.; Sugimoto, N.; Mamun, A.A.; Islam, R.; Hashimoto, M.; Shido, O. Direct exposure to mild heat promotes proliferation and neuronal differentiation of neural stem/progenitor cells in vitro. PLOS ONE 2017, 12, e0190356. [CrossRef] [PubMed]

56. Steiner, A.A.; Romanovsky, A.A. Energy trade-offs in Host Defense: Immunology Meets Physiology. Trends Endocrinol. Metab. 2019, 30, 875-878. [CrossRef]

(C) 2020 by the authors. Licensee MDPI, Basel, Switzerland. This article is an open access article distributed under the terms and conditions of the Creative Commons Attribution (CC BY) license (http://creativecommons.org/licenses/by/4.0/). 